\title{
Lésions varicelleuses photodistribuées chez un garçon de 3 ans
}

\author{
Adrien Mareschal MD, Dominique Blanc MD, François Aubin MD PhD
}

— Citation : CMAJ 2021 March 22;193:E425. doi : 10.1503/cmaj.201771-f

Voir la version anglaise de l'article ici : www.cmaj.ca/lookup/doi/10.1503/cmaj.201771

$\mathbf{U}$

$\mathrm{n}$ garçon de 3 ans a été dirigé vers le service de dermatologie parce qu'il présentait une fièvre de $38,5{ }^{\circ} \mathrm{C}$, de la myalgie et des éruptions vésiculaires bilatérales avec démangeaisons sur les avant-bras et le cou depuis 1 journée (figure 1 et annexe 1 , accessible en anglais au www.cmaj.ca/ lookup/doi/10.1503/cmaj.201771/tab-related-content). Quelques vésicules étaient également réparties sur les régions non exposées à la lumière. Le garçon n'avait pas d'antécédents médicaux et n'avait pas été vacciné contre la varicelle. Son frère aîné avait contracté la maladie 2 semaines plus tôt. Deux jours avant les éruptions, le garçon avait passé l'après-midi à l'extérieur, au soleil, vêtu d'un t-shirt. Une culture de sécrétion de vésicule a confirmé l'infection par le virus varicelle-zona. Nous avons prescrit de l'acétaminophène et de la chlorhexidine aqueuse pour le soulagement des symptômes; les lésions se sont résorbées dans les 2 semaines suivantes.

Jusqu'à $96 \%$ des enfants non vaccinés contractent la varicelle, la plupart du temps avant l'âge de 5 ans $^{1}$. L'infection est caractérisée par la présence simultanée de lésions vésiculaires, érosives et croûteuses, parfois ombiliquées, apparaissant généralement par vagues ${ }^{2}$. Bien qu'elle soit habituellement bénigne - la majorité des enfants sont peu malades -, la varicelle peut s'accompagner de complications, la plus fréquente d'entre elles étant une infection bactérienne surajoutée (impétiginisation) à Staphylococcus aureus ou à Streptococcus pyogenes nécessitant un traitement antibactérien ${ }^{3}$.

On sait que les rayons ultraviolets (UV) exacerbent les infections cutanées herpétiques, mais la présence de lésions varicelleuses photodistribuées est atypique ${ }^{3}$. En cas de maladie caractérisée par des lésions photodistribuées, ces dernières sont légèrement plus grosses que les lésions varicelleuses (généralement 1-2 mm), elles sont monomorphes et elles se trouvent toutes sensiblement au même stade ${ }^{4}$. Le mécanisme pathogénique est méconnu, mais on croit que le rayonnement UV provoque une vasodilatation locale et augmente la perméabilité des capillaires, surtout en cas de virémie ${ }^{4}$. Ce rayonnement induit par ailleurs une immunosuppression locale en stimulant la sécrétion de cytokines anti-inflammatoires, notamment d'interleukine 10 , ce qui pourrait mener à la photodistribution des lésions ${ }^{5}$.

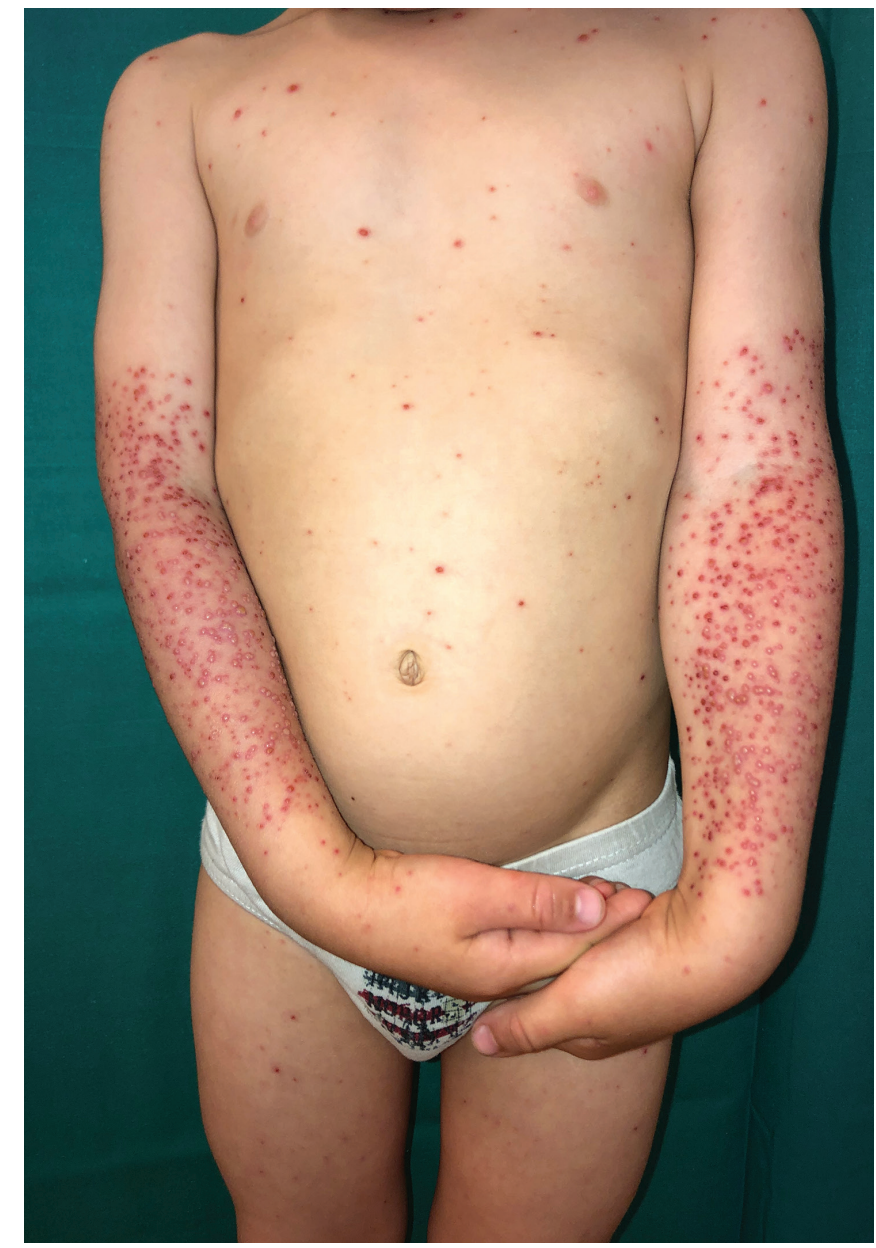

Figure 1 : Vésicules ombiliquées chez un garçon de 3 ans. D'une taille de 2-3 mm, elles étaient accompagnées d'érosions et de croûtes sur les 2 avant-bras.

\section{Références}

1. European Centre for Disease Prevention and Control (ECDC). ECDC guidance: varicella vaccination in the European Union. Stockholm: ECDC; 2015. Accessible ici : https://ecdc.europa.eu/sites/portal/files/media/en/publications/Publications Naricella-Guidance-2015.pdf (consulté le 20 sept. 2020).

2. Sakiyama M, Maeshima $H$, Higashino $T$, et al. Photolocalized varicella in an adult. Br J Dermatol 2014;170:1195-6. 
3. Rodriguez-Santana Y, Sanchez-Almeida E, Garcia-Vera C, et al. PAPenRED. Epidemiological and clinical characteristics and the approach to infant chickenpox in primary care. Eur J Pediatr 2019;178:641-8.

4. Osborne GE, Hawk JL. Photodistributed chickenpox mimicking polymorphic light eruption. Br J Dermatol 2000;142:584-5.

5. Aubin F. Mechanisms involved in ultraviolet light-induced immunosuppression. Eur J Dermatol 2003;13:515-23.

Intérêts concurrents : Aucun déclaré.

Cet article a été révisé par des pairs.

Les auteurs ont obtenu le consentement de la famille du patient.

Affiliations : Service de dermatologie, Centre hospitalier régional universitaire (CHRU) de Besançon, Besançon, France.

Propriété intellectuelle du contenu : Il s'agit d'un article en libre accès distribué conformément aux modalités de la licence Creative Commons Attributions (CC BY-NC-ND 4.0), qui permet l'utilisation, la diffusion et la reproduction dans tout médium à la condition que la publication originale soit adéquatement citée, que l'utilisation se fasse à des fins non commerciales (c.-à-d. recherche ou formation) et qu'aucune modification ni adaptation n'y soit apportée. Voir : https://creativecommons.org/licenses/by-nc-nd/4.0/deed.fr.

Correspondance : Adrien Mareschal, mareschal.adrien@gmail.com

Les images cliniques sont choisies pour leur caractère particulièrement intéressant, classique ou impressionnant. Toute soumission d'image de haute résolution claire et bien identifiée doit être accompagnée d'une légende aux fins de publication. On demande aussi une brève explication (300 mots maximum) de la portée éducative des images, et des références minimales. Le consentement écrit du patient au regard de la publication doit être obtenu avant la soumission. 